\title{
A RELAÇÃO ENTRE DIREITO E MORAL: UMA DISCUSSÃO SOBRE \\ A MORALIDADE EM FERRAJOLI E DWORKIN.
}

\author{
THE RELATIONSHIP BETWEEN RIGHT AND MORAL: A \\ DISCUSSION ON MORALITY IN FERRAJOLI AND DWORKIN.
}

Recebido em 11/09/2017

Aprovado em 27/11/2017

TAINÁ FERREIRA ${ }^{1}$

LUCAS DO COUTO GURJÃO MACEDO LIMA²

RESUMO: Ferrajoli e Dworkin são autores que na busca pela tutela dos direitos individuais procuram formular teorias que discutam e tratem de evitar o decisionismo. A epistemologia dos autores, entretanto, se diferencia quando o garantismo de Ferrajoli assume seu viés positivista, ou seja, uma teoria semântica aos moldes daquelas criticadas por Dworkin. Tendo em vista, a similitude de objetivos dos autores, este artigo procura analisar se haveria uma possibilidade de aproximação entre as construções teóricas no que se refere à relação entre direito e moral. Ao longo da investigação, através da análise da bibliografia dos autores e de críticos, restará demonstrado que a moral rejeitada por Ferrajoli não é a mesma acolhida por Dworkin e que, portanto, os discursos de ambos não são tão distantes assim.

PALAVRAS-CHAVE: Moral; Garantismo; Integridade; Direito; Teoria.

ABSTRACT: Ferrajoli and Dworkin are authors who in the search for the protection of individual rights seek to formulate theories that discuss and try to avoid decisionism. The authors' epistemology, however, differs when Ferrajoli's assertion assumes his positivist bias, that is, a semantic theory along the lines of those criticized by Dworkin. In view of the similarity of the authors' objectives, this article seeks to analyze if there is a possibility of approximation between the theoretical constructions regarding the relation between law and morals. Throughout the investigation, through the analysis of the authors 'and critics' bibliography, it will be shown that the moral rejected by Ferrajoli is not the same accepted by Dworkin and that, therefore, the discourses of both are not so distant.

KEYWORDS: Moral; Garantismo; Integrity; Right; Theory.

\footnotetext{
${ }^{1}$ Mestranda em Direito pela Universidade Federal do Pará. Advogada. Possui graduação em Direito pelo Centro Universitário do Estado do Pará (2015).

2 Mestrando em Direito pela Universidade Federal do Pará - UFPA, na linha Constitucionalismo, Democracia e Direitos Humanos. Graduado em Direito pelo Centro Universitário do Estado do Pará - CESUPA.
} 


\section{INTRODUÇÃO}

Para Dworkin (2014a), o grupo de teorias que buscam identificar os critérios linguísticos que são aplicados para avaliar as proposições jurídicas chama-se teorias semânticas do direito. Trata-se de teorias que não trabalham as divergências quanto ao direito e assim são marcadas pelo aguilhão semântico.

Dessa maneira, tem-se uma crítica direta às teorias positivistas caracterizadas, em geral, pela cisão entre direito e moral. Nesse contexto, destaca-se a teoria garantista de Luigi Ferrajoli, que, nas palavras de Bobbio (2002), se propõe a construir as colunas mestras do Estado de direito, tendo por fundamento fim a tutela das liberdades do indivíduo.

O garantismo é uma teoria positivista e, ainda que Ferrajoli tenha buscado se afastar do que ele chama de paleopositivismo, através da exigência de uma postura crítica e da positivação do dever ser, a cisão entre direito e moral é mantida pelo autor. Diante disto, à primeira vista, poder-se-ia afirmar que seria uma concepção de direito rejeitada por Dworkin, contudo, se ambos os autores buscam a proteção dos direitos individuais e a criação de constrangimentos para a prática do decisionismo dentro do contexto de Estado de direito haveria mesmo esse afastamento?

$\mathrm{O}$ questionamento a ser discutido neste artigo é: Quanto à relação entre direito e moral, seria possível alguma aproximação entre a teoria de Dworkin, o direito como integridade, e a de Ferrajoli, o garantismo?

Dessa maneira, diante da complexidade das construções teóricas dos autores realiza-se um recorte para tratar apenas das noções que envolvem essa relação entre direito e moral, assim, objetiva-se abordar os argumentos apresentados por Ferrajoli e Dworkin para rechaçar ou acolher essa relação, para então discutir se existem traços comuns nas teorias, ainda que a epistemologia aplicada pelos autores seja diferenciada. A hipótese é de que ainda que Ferrajoli seja um crítico da relação entre direito e moral, existem elementos que tornam possível aproximar a sua teoria com a concepção direito como integridade apresentado por Dworkin, na qual a moralidade desempenha um papel fundamental.

Para fins de desenvolvimento do presente trabalho será realizado um apanhado da bibliografia dos autores, isto é, aquela pertinente ao objetivo delimitado, a leitura detalhada de seus trabalhos, a fim de se alcançar a compreensão necessária, bem como a subsequente 
exposição do pensamento de cada um destes pensadores, quais sejam, Ferrajoli e Dworkin, a fim de contrastar as semelhanças e diferenças em suas teorias, de modo a possibilitar a análise de nossa hipótese aqui levantada, de que não há um grande distanciamento ao menos quanto aos fins destes autores. É válido ressaltar que ao longo da pesquisa os termos moral e moralidade serão utilizados como sinônimos.

\section{SOBRE A TEORIA DE FERRAJOLI: O GARANTISMO}

\subsection{JUSPOSITIVISMO CRÍTICO}

Falar de garantismo representa discutir uma teoria considerada como própria do Estado constitucional de direito e que tem por fundamento e fim a tutela das liberdades do indivíduo frente às várias formas de exercício de poder arbitrário, o que é muito latente na seara do direito penal. Ferrajoli, portanto, apresenta em sua obra Direito e Razão (1989) uma visão positivista, mas que não é simplesmente legalista no sentido de mera sujeição à lei, tendo em vista que essa prática pode conviver com más políticas, autoritárias e, portanto, de claro cunho antigarantista (Abellán, 2009).

É de suma importância compreender que Ferrajoli pertence à tradição positivista de Kelsen e Hart, contudo:

[...] é um positivista particularmente atento a distinguir a validez formal, ou vigência, das normas de sua validade substancial e a sublinhar que, em um ordenamento que tenha recepcionado os direitos fundamentais de liberdade, a validez não pode ser apenas formal; que, portanto, existe nesse ordenamento um problema de justiça interna das leis e não só externa: um positivista consciente de que, uma vez produzida na maior parte das constituições modernas a constitucionalização dos direitos naturais, o tradicional conflito entre direito positivo e direito natural, entre positivismo jurídico e jusnaturalismo, tem perdido grande parte de seu significado, com a consciência de que a divergência entre o que é o direito e o que o direito deve ser [...] tem se transformado na divergência entre o que o direito é e o que o direito deve ser no interior de um mesmo ordenamento jurídico, ou, com palavras usadas repetidamente pelo autor, entre "efetividade" e "normatividade" (Bobbio, 2002).

Dessa maneira, um dos pressupostos mais relevantes do modelo garantista é a separação radical entre direito e moral, e dela decorre uma série de outras cisões como a justificação externa e interna, a justiça e validade, o ser e dever ser (Pinho e Albuquerque, 2017). 
A partir disto, cabe destacar os traços principais da teoria garantista. Abellán (2009) afirma que o garantismo é uma tese metodológica que manteve a separação entre ser e dever ser, entre efetividade e normatividade, havendo, portanto, a separação entre direito e moral, entre validez e justiça. A questão da separação entre direito e moral é o ponto onde garantismo e positivismo, de fato, coincidem.

O garantismo, como modelo normativo, entende o Direito como um sistema de limites e vínculos ao poder político para a proteção de bens e interesses que devam ser perseguidos. Assim, enquanto teoria geral impõe um Estado de direito que deve ser concebido como uma rede de garantias no qual há a positivação dos direitos vitais do indivíduo convertendo seu respeito e realização efetiva em um vínculo ao poder político (Abellán, 2009).

No que se refere à questão do ser e dever ser o garantismo parte da base de que o Estado constitucional de direito não é somente o ser, mas também o dever ser das normas positivadas. Dessa forma, o ordenamento positivo não fornece somente as condições de existência ou legitimidade formal das normas, mas também as condições de sua validade ou legitimidade substancial, ou seja, positiva as condições do ser e também do dever ser (Abellán, 2009).

Assim, Ferrajoli apresenta o chamado positivismo crítico, proposta que implica importantes transformações para o modelo de juiz e de ciência jurídica. O Estado constitucional, nesse contexto, incorpora limites e vínculos à produção jurídica e, particularmente, à produção legislativa (Abellán, 2009).

Ferrajoli (2002) afirma que a perspectiva crítica não é externa, ou política ou metajurídica, mas interna, científica e jurídica, de maneira que assume como universo do discurso jurídico o inteiro direito positivo vigente. $\mathrm{O}$ autor sustenta que há um equivocado juspositivismo que confirma comportamentos acríticos, dogmáticos enquanto a perspectiva garantista requer, ao contrário, a dúvida, o espírito crítico e a incerteza permanente sobre a validade das leis e de suas aplicações.

Apresentadas as linhas gerais do garantismo cabe uma atenção maior sobre o que o autor desenvolve acerca das teorias positivistas e, por via de consequência, qual a concepção de moral presente em sua teoria.

Para Figueroa (2009) duas são as ideias básicas defendidas por qualquer positivista: Primeiro, a tese da separação entre direito e moral que significa que o direito pode ter 
qualquer conteúdo, injusto, justo ou moralmente indiferente, de modo que o ser não deve ser confundido com o dever ser. Segundo, a tese da neutralidade onde a descrição do direito deve ser realizada sem valorações, do contrário se confundirá o ser com o dever ser.

Ferrajoli denomina sua teoria como positivismo crítico, isto representa, por um lado, a utilização de uma metodologia positivista e por outro relativiza a tese da neutralidade. Segundo o autor tanto o teórico do direito como o juiz devem avaliar a adequação das normas à constituição para assim poder determinar sua validez, ou seja, isso representa a valoração do direito segundo os preceitos constitucionais (ponto de vista interno) ou puramente morais (ponto de vista externo). (Figueroa, 2009)

Como bem comentam Pinho e Albuquerque (2017), Ferrajoli diferencia o positivismo dogmático do crítico, onde naquele ignora-se o conceito de vigência das normas como categoria independente das de validade e efetividade enquanto no segundo seria um modo de conceber o trabalho do juiz e do jurista de modo a questionar dois dogmas do primeiro modelo: a fidelidade do juiz à lei e a função meramente descritiva e avalorativa do juiz.

O garantismo, portanto, impõe um desafio ao jurista que deve compreender o intricado sistema de valores da Constituição, descobrir o direito inferior, fazer comparação, encontrar os fundamentos formais da vigência e, sobretudo, verificar se materialmente a compatibilidade se apresenta (Pinho e Albuquerque, 2017).

Após todo esse complexo trabalho o juiz deve aplicar o direito positivo ou, verificada a incompatibilidade entre o direito vigente e o direito válido, deve denunciá-lo, de maneira a deslegitimar o comando que estiver em contraste com a norma de grau superior. (Pinho; e Albuquerque, 2017)

Para que isso seja viável sem se atribuir uma função criativa ao juiz, o que se opõe a ideia geral do garantismo, as normas incriminadoras que, porventura, contiverem juízos de valor devem ser avaliadas não segundo as convicções pessoais do juiz, mas conforme os princípios constitucionais (Pinho e Albuquerque, 2017).

O que Ferrajoli faz, portanto, é afastar a possibilidade do decisionismo, recorrendo aos princípios constitucionais como limitadores da atuação jurisdicional nos espaços abertos que, por ventura, venham a ser encontrados na legislação penal infraconstitucional. 


\subsection{AS CRÍTICAS À SEPARAÇÃO ENTRE O DIREITO E A MORAL}

A construção teórica de Ferrajoli, conforme já brevemente comentado, se apoia em dois argumentos centrais o primeiro referente à questão de que a validade substantiva é somente um complemento da validade formal, de modo que a validade das leis não depende somente da forma, mas também da coerência com o conteúdo dos princípios constitucionais, e em um segundo que afirma que a Constituição se origina por uma vontade institucional e não por sua racionalidade ou mérito (Vila, 2009).

Pode-se extrair, então que Ferrajoli não admite a possibilidade de uma relação entre direito e moral fora do âmbito da positivação, insistindo na cisão entre ambos. Por essa razão, o autor considera que essa separação entre justificação ${ }^{3}$ (ou legitimação) externa e interna é um dos pressupostos teóricos e axiológicos do modelo garantista.

A razão para isso repousaria no fato de que a confusão entre as duas legitimações seria sempre solidária com modelos penais de tipo substancialista e autoritário, pois subordina o direito à moral e, portanto ignora a fonte positiva do direito em favor de critérios subjetivos (FERRAJOLI, 2002).

Importante destacar os problemas destes argumentos. $\mathrm{O}$ argumento referente à validade substantiva serve para sustentar que o direito e a moral são sistemas normativos distintos, contudo ao introduzir uma dimensão de validade substantiva como requisito da legalidade se está, ao mesmo tempo, estabelecendo, ainda que por mecanismos internos ao próprio direito, é necessária uma conexão entre direito e moral (VILA, 2009).

Como bem pontuam Pinho e Albuquerque (2017) ainda que a moralidade tenha passado a integrar o sistema através da positivação, sob a forma de princípios constitucionais, ela ainda permanece como moralidade. A mera positivação, portanto, não a transforma ou modifica.

No que se refere ao argumento da vontade institucional, pode-se dizer que Ferrajoli defende que o positivismo admite a presença de princípios e valores morais desde que estes sejam parte do ordenamento jurídico, Vila (2009), entretanto, aponta, dentre diversos

\footnotetext{
3 Ferrajoli (2002) entende por justificação (ou legitimação) externa a legitimação do direito penal por meio de princípios normativos externos ao direito positivo, ou seja, critérios de avaliação moral, políticos ou utilitários de tipo extra ou metajurídico; já a justificação (ou legitimação) interna corresponde à legitimação do direito penal por via de princípios normativos internos ao próprio ordenamento jurídico, mais especificamente, a critérios de avaliação jurídicos, ou seja, intrajurídicos.
} 
problemas, que o fato de a vontade institucional determinar quais princípios serão reconhecidos constitucionalmente gera dificuldades.

Como será enfatizado adiante, a noção de moral rechaçada pelo autor refere-se a uma concepção individualizada, ou seja, uma perspectiva que envolve valores pessoais dos indivíduos e que representaria riscos ao ser integrada ao direito. Este ponto será retomado após a breve análise de um autor que segue o caminho oposto no que se refere à relação entre a moral e o direito.

\title{
3 SOBRE RONALD DWORKIN
}

\subsection{O DIREITO COMO INTEGRIDADE}

Ronald Dworkin por mais de cinco décadas afirmou que existem respostas certas para questões de valor e trabalhou as implicações do direito como prática social. Durante este período, Guest (2012) ressalta que ninguém conseguiu oferecer críticas em grande escala à teoria dworkiana do modo que Hart fez com Bentham e o próprio Dworkin fez com Hart.

Afastando-se da concepção positivista de Ferrajoli, Dworkin apresenta sua teoria do direito como integridade. Conforme Guest (2012) ressalta, Dworkin prefere a caracterização do direito (law) como uma atitude argumentativa do que como modelo de regras e é por isso que a mais coerente, consistente e avançada sistematização da verdadeira moral toma lugar em sua teoria.

\begin{abstract}
His theory of interpretation is that our value concepts are inherently controversial and we must make "best sense" of them; in the case of ethical and moral value this means making the best ethical and moral sense. His theory of ethics is that we each have a duty to make our own lives valuable. His theory of morality, like Kant's, is that we should treat others as having lives that are equally valuable to our own while also observing our duty to make our own lives valuable; he therefore thinks our ethics - our "living well"-allows competition with others where such competition falls short of harming them (Guest, 2012).
\end{abstract}

Dworkin, portanto, se propõe a caracterizar a melhor justificação possível para as decisões que afetam pessoas. Ele pensa que não é possível extrair muito somente descrevendo como o direito é. Sua percepção das regras e instituições - prática social do direito- deve ser permeada pelo julgamento das pessoas, ou seja, deve-se extrair sempre o melhor sentido 
dessas práticas sociais. (Guest, 2012) A maior preocupação da teoria moral e política de Dworkin repousa sobre o que se pode chamar de princípio fundacional que consiste na premissa de que as pessoas devem ser tratadas com igual consideração e respeito.

Dworkin possui uma característica muito importante que é a dificuldade de classificálo. Conforme Guest ressalta, ele não se encaixa em categorias ortodoxas. Sua teoria pretende ser prática, no sentido mais óbvio, e nega qualquer distinção importante entre o mundo real e abstrato. Diante disto, é essencial dizer que o interesse do autor está nos problemas da justificação moral do direito, Estado e na moralidade (Guest, 2012).

A construção teórica de Dworkin é marcada pelo debate que foi travado com Hart ao longo de sua vida. Para Hommerding e Lira (2015), a ideia do autor passa primeiro pela não aceitação da tese esposada pelo positivismo jurídico de Hart, quando este afirma que nos casos que em que não há uma regra jurídica prevista o juiz estaria legitimado a usar da discricionariedade para a busca da solução.

Para Dworkin (2014a) o direito é um conceito interpretativo, os juízes desenvolvem, em respostas às suas próprias convicções e tendências, teorias operacionais sobre a melhor interpretação de suas responsabilidades no desempenho de sua função. As divergências que venham a surgir sobre essas teorias são consideradas pelo autor como divergências interpretativas.

Na obra $O$ império do direito (1986), o autor trabalha com três concepções acerca do direito. O convencionalismo e o pragmatismo marcam uma característica de Dworkin que é a de apresentar uma série de doutrinas de maneira sistematizada no que ele entende ser a melhor luz, ou seja, trata-se de uma reconstrução, feita pelo autor, de teorias que ele considera rivais. Além dessas duas, o autor apresenta o direito como integridade que, segundo ele, será a melhor concepção dentre as apresentadas.

O direito como integridade 4 , portanto, seria uma terceira opção entre o convencionalismo e o pragmatismo, de maneira a oferecer um suporte de padrões para as decisões tomadas pelo julgador nos casos concretos. A integridade seria a chave da melhor

\footnotetext{
4 De acordo com Pinho (2013) não é possível apresentar conceitos semânticos sobre os aspectos desenvolvidos por Dworkin, pois isso seria contraditório com sua própria teoria que rechaça esse tipo de objetividade. No entanto, a fim de esclarecer o que seria o direito como integridade, a autora afirma que na teoria dworkiana qualquer decisão jurídica deve passar pelos testes de adequação e justificação, ambos são testes de integridade e buscam atender as exigências da moralidade política, característica principal da concepção desenvolvida pelo filósofo. Trata-se de aspectos complexos cujo desenvolvimento extrapola o objetivo deste artigo.
} 
interpretação construtiva das diferentes práticas judiciais, em especial, quando os julgadores estão diante de um caso difícil (Hommerding e Lira, 2015).

Essa, portanto, seria a única concepção capaz de gerar decisões justas, argumentativamente construídas, equilibradas, que, portanto, mantem a coerência com o que já foi produzido pelas instituições jurídicas sem, entretanto, ficar atrelado ao passado, podendo justificar o rompimento de paradigmas ou precedentes com base em razões fundadas em princípios de moralidade política (Pinho, 2013).

De acordo com Palombella (2005), para Dworkin não há um direito positivo em si, mas todo direito "positivo" é fruto de uma prática interpretativa e argumentativa que o constitui e reformula no tempo. Dessa maneira,

\begin{abstract}
O direito é sempre reconstruído, portanto, como integrity, congruência, e esta exige que o "juiz sempre que possível, trate o sistema de standards públicos vigentes como se expressasse e respeitasse um conjunto coerente de princípios e, para tal fim, que interprete esses standards de tal modo que encontre standards implícitos entre os explícitos e por trás deles". [...] O direito como integridade postula a interpretação como método e prática geral do discurso jurídico e do metadiscurso dos juristas e dos teóricos do direito, diz respeito a easy e hard cases, pressupõe que a existência de textos normativos de significado incontroverso não constitui uma especifica zona de luz não passível de reconstrução (e reformulação) global dentro do sistema jurídico (Palombella, 2005).
\end{abstract}

Para Palombella (2005) a teoria de Dworkin assume uma função "construtivista" da atividade judiciária e dos juristas em geral, o que o sujeita a objeções que exigem a limitação "positiva" da atividade judiciária, de maneira a reprovar a excessiva liberdade criativa e falta de vínculos jurídicos e interpretativos eficazes.

\title{
3.2 MORALIDADE EM DWORKIN
}

A análise da moralidade para Dworkin não pode se dedicar a definir um conceito semântico, pois, como bem destaca Pinho (2013) isto seria contraditório com a própria tese do autor. Dessa maneira, a moralidade trabalhada pelo autor busca construir uma interpretação na qual os argumentos morais se integram ao direito, na medida em que as decisões devem ser tomadas, de acordo com o cumprimento de parâmetros de justiça, equidade e integridade, em uma comunidade de princípios. 
Para Dworkin (2014b), há um quadro ortodoxo que busca explicar a relação entre o direito e a moral. Neste quadro as palavras "direito" e "moral" designariam conjuntos de normas diferentes, onde o primeiro pertenceria a uma comunidade particular e seria, ao menos em grande parte, feito pelos seres humanos, enquanto a segunda consistiria em um conjunto de normas ou padrões que se impõem imperativamente a todos e que não seria criada por ninguém (salvo em teorias que atribuem essa função a um deus), de modo a não depender de nenhuma decisão ou prática humana.

Essa descrição feita pelo autor remete a uma noção comum sobre a moral, de maneira, que alguns filósofos rejeitam essa descrição, em especial no que se refere à origem da moral, contudo a grande maioria admite que se tratam de sistemas normativos diferentes e que suas ligações são problemáticas (DWORKIN, 2014b).

Dworkin considera que há uma falha nessa imagem de dois sistemas distintos.

\begin{abstract}
Quando partimos do princípio de que o direito e a moral constituem sistemas normativos separados, já não há nenhum ponto de vista neutro a partir do qual os vínculos entre esses dois sistemas supostamente separados possam ser avaliados. Onde devemos buscar a resposta à questão de saber se é o positivismo ou o interpretacionismo a teoria mais precisa, ou a melhor, acerca da relação entre os dois sistemas? Essa questão é jurídica ou moral? Ambas as opções geram argumentos circulares de raio extremamente curto (Dworkin, 2014b).
\end{abstract}

Diante disto, o autor substitui essa visão de sistemas separados pela imagem de um só sistema de modo que o direito seria uma parte da moral política. Dworkin (2014b) trabalha com uma estrutura em forma de árvore, na qual a moral pessoal deflui da ética e a moral política da moral pessoal.

Na obra A raposa e o porco espinho (2014) Dworkin estuda a ética e moral pessoal através do conceito de responsabilidade e não de direito, já que, para o autor, trata-se de um enfoque mais adequado uma vez que ao pensar no que é viver bem, é mais natural e exato pensar naquilo que cada pessoa tem a responsabilidade de fazer e não no que se tem direito de exigir (Dworkin, 2014b).

Deve-se ressaltar, entretanto, que quando se entra no campo da moral política a ideia de direitos é muito mais adequada do que a abordagem de deveres e obrigações com a qual a moral pessoal, através da análise da responsabilidade, foi trabalhada. Assim, sob essa ótica os indivíduos tem direitos políticos, e pelo menos alguns deles correspondem não aos deveres de indivíduos particulares, mas aos deveres coletivos da comunidade (Dworkin, 2014). 
É válido esclarecer que Dworkin (2014b) trabalha os direitos políticos como trunfos, ou seja, trunfos contra justificativas de ação política que, de outro modo, seriam adequadas. Dessa maneira,

\begin{abstract}
Uma comunidade política não tem poder moral para criar e impor obrigações contra seus membros a menos que os trate com igual consideração e respeito, ou seja, a menos que, em seus programas de ação política, considere todos os seus destinos como igualmente importantes e respeite a responsabilidade individual de cada um deles pela própria vida. Esse princípio de legitimidade é a fonte mais abstrata dos direitos políticos. O governo não tem autoridade moral para coagir ninguém, nem mesmo com a finalidade de aperfeiçoar o bem-estar da comunidade como um todo, a menos que respeite essas duas exigências no que se refere a cada indivíduo (Dworkin, 2014b).
\end{abstract}

A moralidade em Dworkin refere-se a um consenso na comunidade que, portanto, representa algo mais profundo do que a mera descrição dos que as pessoas, em determinado momento, pensam ou sentem. Para o autor, portanto, a moralidade não é constituída por convenções públicas que dizem que condutas são moralmente requeridas ou permitidas de acordo com que a maioria das pessoas pensa. Um consenso significa uma coincidência das mesmas convicções (Guest, 2012).

Dworkin, portanto, rejeita a possibilidade de escolhas arbitrárias ao afirmar que o juiz deve decidir com base em princípios da moralidade política, ou seja, a fundamentação das decisões é imprescindível. O limite ao decisionismo vem da fundamentação coerente, com base nos princípios que exsurgem da tradição (Pinho, 2013).

O sentido de moralidade política é, justamente, o argumento central contra esse decisionismo, já que Dworkin reconhecendo que toda decisão judicial é política, afirma que se deve entender esse "política" no sentindo de moralidade política, ou seja, fundado em princípios, ideias de justiça, do que é melhor para uma determinada comunidade, levando em conta sua história, tradição e não na moralidade comum, baseada em concepções subjetivas (Pinho, 2013).

\title{
4 DISCUTINDO DWORKIN E FERRAJOLI: A MORALIDADE NO DIREITO
}

Apresentadas as linhas gerais das construções teóricas de Ferrajoli e Dworkin fica bem claro que uma das diferenças mais marcantes entre os autores é a relação existente entre 
direito e moral. Ferrajoli rechaça essa relação apontando os malefícios que ela traz, enquanto que Dworkin coloca a moralidade como essencial ao direito, já que somente ela pode oferecer a justificação necessária.

Aparentemente as teorias dos autores parecem se contrapor, contudo, o fato de Ferrajoli tratar o positivismo de uma maneira crítica remete à necessidade de uma análise mais cuidadosa em especial quando se está diante de uma teoria como a de Dworkin que aparentemente opta por um caminho inverso.

Para Ferrajoli (2002), na linha das teorias jusnaturalistas, o risco do substancialismo e da confusão entre direito e moral está, principalmente, naquelas ideologias positivistas e nos modelos de direito penal que conferem caráter absoluto ao poder do legislador de predeterminar os delitos e as penas. Dessa maneira,

\begin{abstract}
As doutrinas que legitimam sistemas penais substancialistas e autoritários - como aquelas positivistas do "delinquente natural" e da "defesa social", ou aquelas subjetivas do "tipo de autor" ou do "direito penal da vontade" - são doutrinas que, principalmente, admitem ou recomendam a inclusão na lei de critérios avaliadores e de referências indeterminadas, em reforço a um princípio de legalidade penal compreendido não em sentido "estrito", mas em sentido "lato" ou "mero" ou "atenuado", e que, consequentemente, mesmo atrelando à lei a definição de desviação punível, reclama, de fato, a integração judiciária com elementos extralegais de tipo substancialista e largamente arbitrários, em razão do caráter não taxativo consentido às previsões legais (Ferrajoli, 2002).
\end{abstract}

Ferrajoli (2002) afirma, então, que em relação ao direito penal são duas as vias que negam a separação entre direito e moral ou a confusão entre os seus diversos significados. $\mathrm{O}$ substancialismo rejeita o princípio normativo da separação e se liga a doutrinas relacionadas à ideia de uma base ontológica do direito penal, e, via de consequência, a uma renovada confusão jusnaturalista com a moral ou com a natureza. Trata-se, por exemplo, de várias correntes católicas e espiritualistas do moralismo e do caráter pedagógico do direito penal (Ferrajoli, 2002).

O formalismo, por sua vez, renuncia a qualquer ponto de vista externo. Neste caso, tem-se uma adesão positivista à tese teórica da separação entre direito e moral e que, confundindo tal tese com a axiológica, chega à assunção do ponto de vista jurídico como o único admissível inclusive para fins de justificação ético-jurídica do direito penal (Ferrajoli, 2002). 
Essa concepção merece destaque, pois, em síntese, submete a moral ao direito de modo a valorizar a forma jurídica, independentemente do seu conteúdo e que assume o direito e o Estado enquanto valores éticos em si (Ferrajoli, 2002).

\begin{abstract}
Compreende-se, assim, como o formalismo ou positivismo jurídico de tipo ético, valorizando o direito enquanto tal, seja idôneo a fundar doutrinas sobre a ausência de limites do poder do Estado, cujo êxito extremo é o fascismo. O princípio de (mera) legalidade [...] é, de fato, aceito em tais ideologias como o único postulado axiológico (e não meramente teórico) em razão do qual possui valor (e não apenas vigor) qualquer conteúdo normativo (quod principi placuit). A forma jurídica, por seu turno, não é reivindicada como instrumento ou garantia de tutela de valores ou de interesses externos ao Estado, mas enquanto valor em si própria, exclusivo e exaustivo, não condicionado por limites e garantias tais como estrita legalidade e outros direitos dos cidadãos (Ferrajoli, 2002).
\end{abstract}

Assim, para expor a problemática da existência de uma relação do direito com a moral Ferrajoli (2002) ressalta que nas doutrinas políticas e jurídicas utilizadas durante o período nazista, a transformação ética do direito fez com que o princípio da legalidade passasse a ser o irracional e decisionista Führerprinzip consentindo no ingresso, no âmbito penal, de figuras como um direito penal do autor ou do inimigo, consubstanciados na figura de um povo ou Estado.

A preocupação do autor, portanto, é de demonstrar que as decisões de caráter penal, sejam legislativas ou jurisdicionais, precisam estar fincadas em critérios de máxima racionalidade e certeza para evitar o favorecimento do autoritarismo e do arbítrio, como o ocorrido durante o Nazismo. Quanto maior a incerteza e obscuridade das esferas de poder, maior será a insegurança do cidadão e maior será o risco a sua liberdade (Pinho e Albuquerque, 2017).

Dworkin (2014a) menciona a crítica realizada por alguns filósofos de que em alguns países, ou em determinadas situações (como no caso do Nazismo), o direito não existe, a despeito da existência de instituições jurídicas, como as legislaturas e os tribunais, porque as práticas de tais instituições são por demais iníquas para serem dignas desse nome.

Isto porque, já que as teorias direito são interpretativas é possível entender que tais práticas jurídicas não produzem, na esfera de qualquer moralidade pública, qualquer justificação aceitável (Dworkin, 2014a). 
A importância desta percepção repousa no fato de que no apogeu das teorias semânticas 5 havia uma preocupação dos filósofos com a sugestão de que não havia direito nos lugares perversos. Tratava-se da necessidade de se utilizar do termo "direito" de maneira geral, a fim de abranger as declarações de um povo não só sobre seu próprio direito, mas também sobre sistemas jurídicos de épocas e países diversos (Dworkin, 2014a).

Dworkin (2014a), então, se volta para a necessidade de extrair o aguilhão semântico e abandonar a necessidade de se preocupar com a resposta certa à pergunta sobre se existe ou não direito nos sistemas imorais. Como ressalta o autor,

\begin{abstract}
[...] não se segue daí que, se um advogado encontrar a melhor interpretação do direito anglo-americano em algumas características totalmente ausente do regime nazista, ele deva negar que os nazistas tinham direito. Sua teoria não é uma teoria semântica sobre todos os usos da palavra "direito", mas uma teoria interpretativa sobre as consequências de adotar a atitude interpretativa com relação ao seu próprio sistema jurídico. Ele pode, com total propriedade linguística, insistir em que os nazistas tinham, de fato um direito. Entenderíamos o que ele estaria tentando dizer. [...] Ele estaria querendo dizer que o sistema nazista pode ser reconhecido como um dos fios da corda, uma realização histórica das práticas e instituições gerais a partir das quais se desenvolveu nossa própria cultura jurídica. Dito de outra forma, é direito no sentido que chamamos de "pré-interpretativo"(Dworkin, 2014a).
\end{abstract}

O filósofo procura afirmar que não é necessário negar que o Nazismo foi um tipo de direito, porque há um sentido válido em que se tratava, claramente, de direito. Este entendimento, entretanto, não gera dificuldades de compreender quando alguém diz que a lei nazista não constituía direito, ou que era direito em um sentido degenerado (Dworkin, 2014a).

Dworkin (2014a) procura, através dessa análise, demonstrar que teorias semânticas, como o positivismo, limitam a linguagem ao não permitir que se use a palavra direito de modo flexível. Trata-se de um estudo diferenciado daquele realizado por Ferrajoli e que, por sua vez, busca ressaltar a importância da sensibilidade ao contexto e da compreensão de que as teorias do direito são interpretativas.

Percebe-se, portanto, que o foco do autor não está em uma análise semântica do que é ou não direito. Para ele os verdadeiros problemas de sistemas jurídicos como o que se respaldou o Nazismo referem-se à moral política, ao papel das instituições entre outros. Dessa maneira, chama atenção como Ferrajoli e Dworkin referem-se a um mesmo fato - o

\footnotetext{
5 Conforme apresentado na introdução deste artigo, as teorias semânticas são aquelas que, de acordo com Dworkin (2014a), são marcadas pelo aguilhão semântico, ou seja, que buscam identificar os critérios linguísticos que são aplicados para avaliar as proposições jurídicas. Como bem coloca Pinho (2013) trata-se de teorias cujo foco repousa na precisão semântica, pautada em limites objetivos a serem dados pela linguagem.
} 
autoritarismo e violações de direitos decorrente de tais situações -, contudo, com perspectivas diferentes de tratar a relação entre o direito e a moral.

Conforme já abordado, um dos pontos centrais de Dworkin é a sua concepção de moralidade política que vai além de uma concepção individual do que as pessoas pensam ou não. Dworkin, portanto, não acredita na precisão semântica e tampouco em limites objetivos a serem dados pela linguagem per se, o que se apresenta também como um dos cernes da teoria de Ferrajoli (Pinho, 2013).

Deve-se ressaltar, entretanto, que apesar das diferenças entre os autores aqui abordados, ambos, conforme suscita Pinho (2013), buscam o controle para o poder de decisão do juiz, o que fica bem claro pelas críticas que eles trazem acerca do decisionismo.

Assim, as críticas que Ferrajoli traça sobre a associação da moral com o direito são pertinentes, entretanto, não invalidam a teoria dworkiana, pois o sentido de moral explorado por Ferrajoli não corresponde à moralidade política apresentada por Dworkin. Dessa maneira, quando se fala em uma possibilidade de aproximação entre as teorias estar-se a referir aos apontamentos em comum realizados pelos autores.

Tanto Ferrajoli quanto Dworkin mostram-se preocupados com uma moral que leve a subjetivação e que, portanto, favoreça a incerteza e obscuridade e buscam através de suas concepções teóricas traçar diretrizes para evitar tais imprecisões. Se a cisão entre direito e moral é uma das marcas do garantismo, deve-se atentar para qual o tipo de moral que vem a ser criticada.

Percebe-se, então que não é possível afirmar a incompatibilidade absoluta entre os autores, pois tal uma declaração nesse sentido demonstraria uma falta de alinhamento entre essas concepções, o que não ocorre, pois em uma análise mais detalhada o que se nota é que ambos possuem uma grande proximidade nos objetivos de suas teorias.

Pinho (2013) afirma que direito e moral não podem ser separados porque a produção do direito está, desde sempre, imersa na moralidade política e no conjunto de tradições que (con)formam determinada sociedade, não se podendo disso escapar. Ainda quando, posteriormente, Ferrajoli enfim reconhece certa relação entre direito e moral ele a entende no seguinte sentido, 


\begin{abstract}
Pelo que se percebe das recentes manifestações de Ferrajoli [...] quando afirma que seria ingenuidade sustentar uma separação total entre moral e direito - porque ao menos os legisladores, ao fabricarem normas, teriam opiniões morais sobre aquele tema - assume essa moralidade num viés bastante reducionista, como sinônimo de opinião pessoal, subjetiva ou visão de mundo sobre algo. É essa moral ( uma "moral comum", ou uma "moral enquanto tal") que Ferrajoli afirma ser indissociável de qualquer conteúdo jurídico. Porém [...] não é desta moralidade que se trata. Não é essa moral que se pretende seja implicada ao direito (Pinho, 2013).
\end{abstract}

Para Ferrajoli o caráter não impessoal do juiz é um dos fatores que causam a incerteza da verdade, pois ele sempre estará condicionado pelas circunstâncias ambientais, por seus sentimentos, suas emoções, valores ético-políticos etc. Dworkin se posiciona exatamente contra isso, de modo que o juiz ainda que condicionado por fatores subjetivos, o que é inevitável, sua decisão não poderia ser fruto dessa moral subjetiva pessoal, ela deveria ser baseada em princípios de moralidade política (Pinho, 2013).

Para Pinho (2013) o garantismo, de fato, representa um avanço ao paleopositivismo, contudo ele não é suficiente para o afastamento do decisionismo, pois ainda se encontra preso a uma teoria semântica do significado. Não se trata, contudo, de corrigir a teoria de Ferrajoli, dada a importância que o garantismo segue tendo nos sistemas jurídicos democráticos, apenas se está apontando os óbices existentes para a construção de uma teoria da decisão penal que satisfaça os anseios de limitar o poder do juiz.

Para Hommerding e Lira (2015) a integridade dworkiana é contrária à discricionariedade, pois aquela é um ideal e se vincula à interpretação do direito que deve se aperfeiçoar constantemente. Dessa maneira, o direito como integridade usa do princípio da integridade como forma de limitar o campo discricionário ou arbitrário nas decisões judiciais.

No mesmo sentido, a preocupação de Ferrajoli, no campo penal, é de que se criminalizem comportamentos meramente imorais, de maneira a confundir crime com pecado, entretanto essa proibição de que os aspectos da moral comum orientem as proibições penais pode ser realizada por outros mecanismos (hermenêuticos) e não da irreal cisão entre direito e moral (Pinho e Albuquerque, 2017).

Como bem destaca Pinho (2013) Ferrajoli não admite essa implicação tão direta com a moral, pois ele não crê que os juízes podem dar conta dos valores morais, de maneira que podem acabar envolvendo sua moralidade subjetiva, portanto seria melhor que se mantivessem livres da moralidade e se pautem somente nos princípios que estejam positivados. 
Deve-se ressaltar, entretanto, que decidir corretamente implica decidir politicamente, com base em princípios, e mais uma vez se enfatiza a crítica ao garantismo, pois quando Ferrajoli afirma que os princípios uma vez que estejam positivados perdem seu conteúdo moral deve-se questionar,

Será isso possível? Para a integridade, seguramente, não. Os juízos morais, como se vem de demonstrar, são interpenetrados no Direito. A dualidade moral x direito, que vem de uma separação unicamente semântica, é fortemente rejeitada pela teoria do direito como integridade. Os princípios devem conduzir, em suma, à melhor interpretação moral do direito (Pinho, 2013).

Justificar o direito penal com base nos princípios é fazê-lo, inegavelmente, a partir de critérios da moralidade, já que esses princípios continuam a serem exigências da moralidade (Pinho e Albuquerque, 2017). Isto pode muito bem ser sustentado quando se considera a moralidade nos termos que Dworkin apresenta e embasa sua teoria.

O que se percebe da análise das teorias aqui trabalhadas é que os autores buscam a realização de uma teoria sobre o direito que forneça obstáculos ao decisionismo, contudo ao seguirem fundamentos teóricos diferenciados uma aproximação parece, à primeira vista, inviável. No entanto, quando se analisa a moralidade que procura ser evitada em ambas as construções teóricas fica perceptível que ela se assemelha, pois é consubstanciada em uma visão individual, pessoal.

\section{CONCLUSÃO}

Ao longo desse artigo notou-se que a afirmação de que o garantismo é uma teoria juspositivista (ainda que crítica) remete a ideia básica da separação entre direito e moral, epistemologia comum a diversas abordagens positivistas, o que causa estranheza e aparente incompatibilidade com a teoria dworkiana do direito como integridade que se respalda na concepção de moralidade política.

Após um breve estudo acerca das noções trabalhadas pelos autores percebeu-se que ambos compartilham o objetivo de traçar barreiras ao decisionismo e ao poder arbitrário que viole direitos individuais e, com base nisso, rejeitam ou acolhem uma relação entre direito e moral. 
Todavia, quando se analisa a justificativa de Ferrajoli para rechaçar a existência de uma relação entre direito e moral, fica claro que a moral discutida pelo autor não corresponde ao que Dworkin chama de moralidade política. Dessa maneira, nota-se que ambos os autores se aproximam em suas críticas, ambos rejeitam visões individualizadas e subjetivas que conduzem às arbitrariedades e ambos destacam a importância dos princípios em suas construções teóricas.

Assim, a hipótese apresentada se confirma, tendo em vista que, a moral que conduz ao decisionismo é rechaçada tanto por Ferrajoli quanto por Dworkin, e esta não corresponde à moralidade política existente no direito como integridade. Percebe-se, então que os fins das teorias são semelhantes, entretanto é preciso atentar para o fato de que a manutenção do garantismo como teoria positivista gera limitações e críticas na linha das que aqui foram apresentadas.

Não se tratam de teorias contrapostas, como a primeira vista pode parecer, a relevância dos autores reside justamente no propósito de traçar barreiras para arbitrariedades e preservar o Estado democrático de direito, por meio do desenvolvimento de parâmetros decisórios.

Resta claro, então que uma aproximação entre os autores é possível quando se trabalha a fundo as noções que compõem suas teorias, mas ao estabelecer a relação com o direito como integridade, percebe-se a problemática que é manter a epistemologia garantista na forma de um juspositivismo crítico.

Importante ressaltar que as críticas ao garantismo não diminuem sua a importância pois, como foi comentado, trata-se de uma teoria de extrema relevância para a sustentação de um Estado democrático, contudo, é necessário esclarecer que a manutenção da cisão entre direito e moral é uma árdua sujeita a diversas críticas.

Não se pode negar que ambas as teorias abordadas possuem muitos outros aspectos complexos que merecem ser trabalhados, contudo, discutir a relação entre direito e moral demonstra que para além de meras classificações, é importante compreender o que justifica a posição dos autores, pois somente por este caminho entende-se que o fim buscado segue sendo o de tutelar direitos fundamentais contra decisões subjetivas e que não condizem com qualquer expectativa de justiça e equidade. 


\section{REFERÊNCIAS}

ABELLÁN, Marina Gascón. La teoría general del garantismo: Rasgos principales. In CARBONELL, Miguel; SALAZAR, Pedro. Garantismo: Estudos sobre el pensamento jurídico de Luigi Ferrajoli. Madrid: Editorial Trotta, 2009.

BOBBIO, Norberto. Prefácio. In: FERRAJOLI, Luigi. Direito e razão: teoria do garantismo penal. São Paulo: Editora Revista, 2002.

DWORKIN, Ronald. O Império do Direito. 3 ed. São Paulo: Martins Fontes, 2014a.

$2014 \mathrm{~b}$.

A raposa e o porco-espinho: justiça e valor. São Paulo: WMF Martins Fontes,

FERRAJOLI, Luigi. Direito e razão: teoria do garantismo penal. São Paulo: Editora Revista, 2002.

FIGUEROA, Alfonso Garcia. Las tensiones de una teoría cuando se declara positivista, quiere ser crítica, pero parece neoconstitucionalista: A propósito de la teoría del derecho de Luigi Ferrajoli. In CARBONELL, Miguel; SALAZAR, Pedro. Garantismo: Estudos sobre el pensamento jurídico de Luigi Ferrajoli. Madrid: Editorial Trotta, 2009.

GUEST, Stephen. Ronald Dworkin. 3 ed. California: Stanford University Press, 2013.

HOMMERDING, Adalberto Narciso; LIRA, Cláudio Rogério. A teoria do direito como integridade de Ronald Dworkin como condição para a positivação do direito. Revista Faculdade Direito Sul de Minas, Pouso Alegre, v.31, n.1, p.97-122, jan/jun 2015.

PALOMBELLA, Gianluigi. Filosofia do Direito. São Paulo: Martins Fontes, 2005

PINHO, Ana Cláudia Bastos de. Para Além do Garantismo: Uma proposta hermenêutica de controle da decisão penal. Porto Alegre: Livraria do Advogado, 2013.

; ALBUQUERQUE, Fernando da Silva. Precisamos falar sobre garantismo: limites e resistência ao poder de punir. Florianópolis: Empório do Direito, 2017.

VILA, Marisa Iglesias. El positivismo en el estado constitucional: Algunos comentários en torno al constitucionalismo de Ferrajoli. In CARBONELL, Miguel; SALAZAR, Pedro. Garantismo: Estudos sobre el pensamento jurídico de Luigi Ferrajoli. Madrid: Editorial Trotta, 2009. 